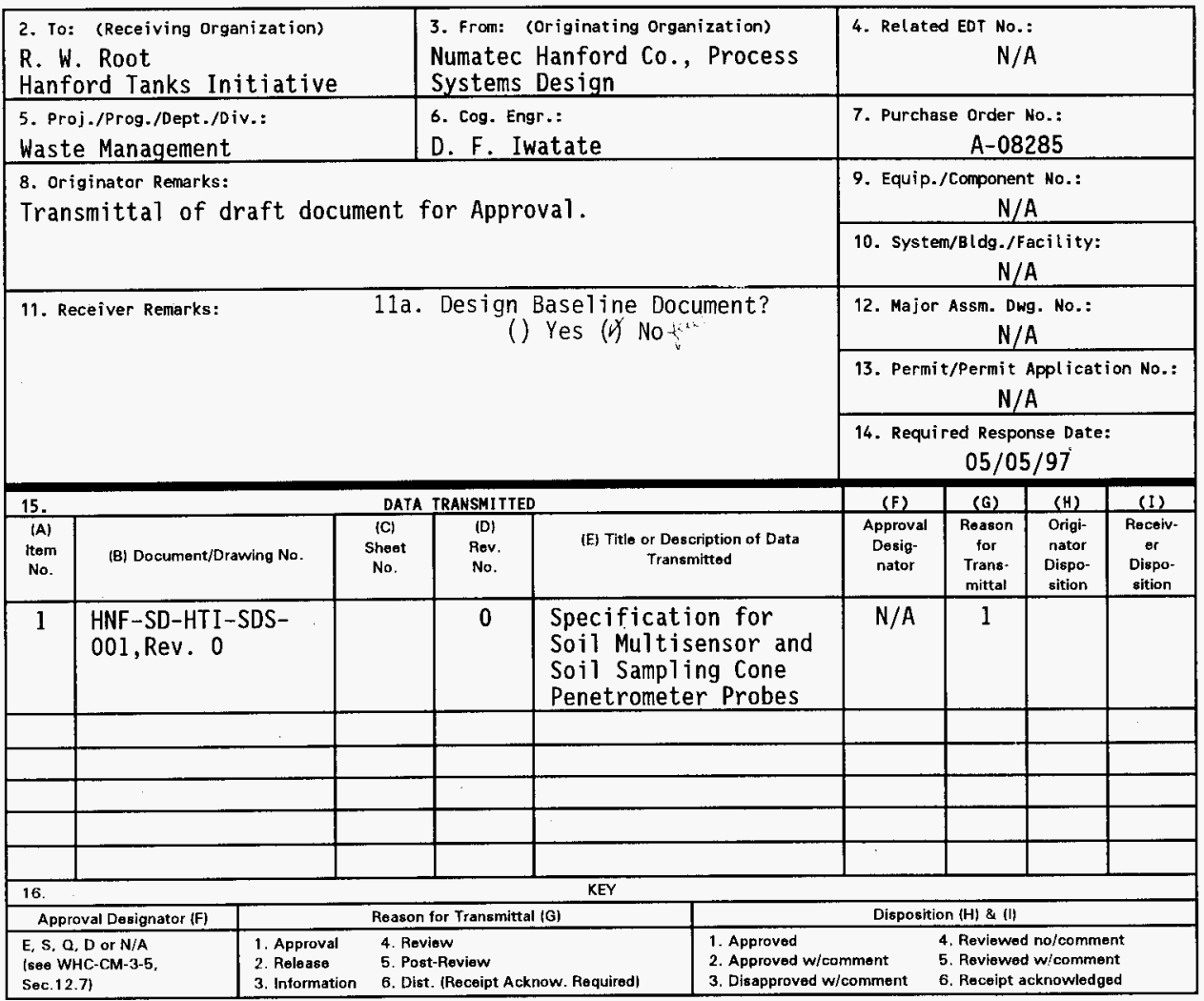

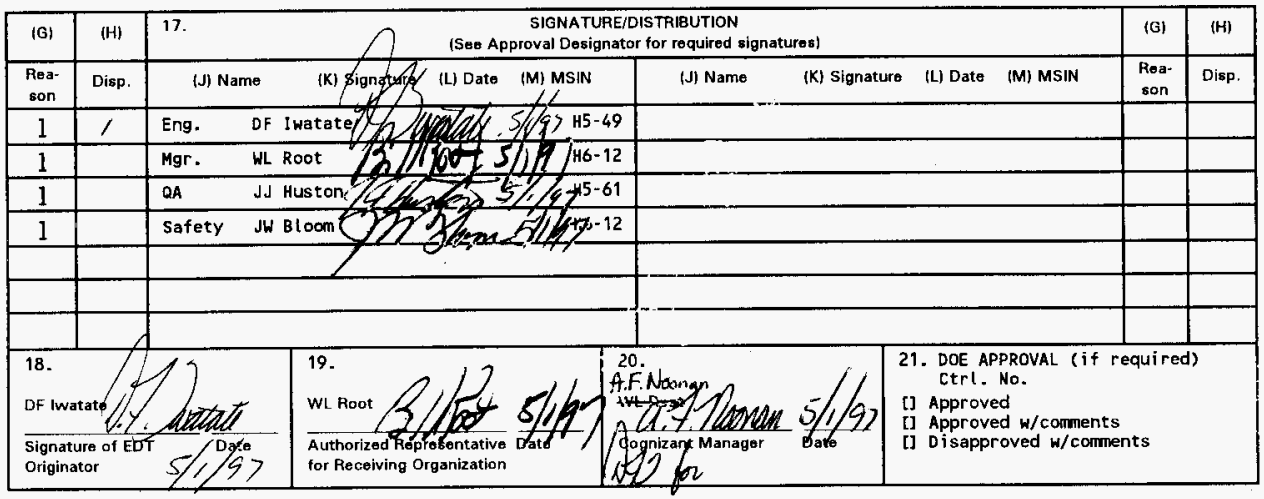




\title{
Specification for Soil Multisensor and Soil Sampling Cone Penetrometer Probes
}

\author{
D. F. Iwatate
}

Numatec Hanford Company, Richland, WA 99352-1300

U.S. Department of Energy Contract DE-AC06-96RL 13200

$\begin{array}{lll}\text { EDT/ECN: } & 620513 & \text { UC: } 2030 \\ \text { Org Code: } & 73500 & \text { Charge Code: E62030 } \\ \text { B\&R Code: } & \text { EW3130010 } & \text { Total Pages: } 18\end{array}$

Key Words: Single-She11 Tanks, waste, plume, cone penetrometer, gamma, sray fluorescence, vadose zone, soil

Abstract: Specification requirements for engineering, fabrication, and performance of cone penetrometer (CP) soil multisensor and sampling probes (CP-probes). Required to support contract procurement for services. The specification provides a documented technical basis of quality assurance that is required to use the probes in an operating Hanford tank farm. The documentation cited in this specification will be incorporated into an operational fielding plan that will address all activities associated with the use of the CP-probes. The probes discussed in this specification support the Hanford Tanks Initiative AX104 Tank Plume Characterization Sub-task. The probes will be used to interrogate soils and vadose zone surrounding tank $A X-104$.

TRADEMARK DISCLAIMER. Reference herein to any specific commercial product, process, or service by trade name, trademark, manufacturer, or otherwise, does not necessarity constitute or imply its endorsement, recomendation, or favoring by the United States Government or any agency thereof or its contractors or subcontractors.

Printed in the United States of America. To obtain copies of this document, contact: WHC/BCS Document Control Services, P.O. Box 1970, Mailstop H6-08, Richland WA 99352, Phone (509) 372-2420; Fax (509) 376-4989.
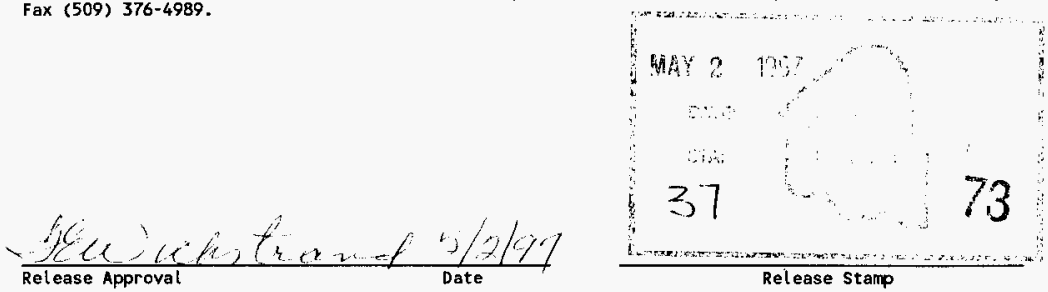


\title{
SPECIFICATION FOR SOIL MULTISENSOR AND SOIL SAMPLING CONE PENETROMETER PROBES
}

\author{
Prepared by: \\ D. F. Iwatate \\ Numatec Hanford Corp.
}

May 2, 1997 
HNF-SD-HTI-SDS-001, Rev. 0

\section{Table of Contents}

\subsection{SCOPE}

\subsection{BACKGROUND}

\subsection{TECHNICAL OVERVIEW}

\subsection{CONE PENETROMETER PROBE REQUIREMENTS}

4.1 General Requirements for CP Probes

4.2 Multisensor Probe
4.2.1 Gamma Spectroscopy (GS) Detector System

4.2.2 X-ray Fluorescence System

4.2.3 Soil Stratigraphy

4.2.4 Magnetometer and Inclinometer

4.2.5 Grouting Module

4.2.6 Umbilical (signal) Cable to Multisensor Probe

4.3 Multi-sample Soil Sampler Probe

5.0 MATERIALS OF CONSTRUCTION

6.0 PERFORMANCE VERIFICATION
6.1 Acceptance Testing
6.2 Calibration of Instruments

7.0 DOCUMENTATION

7.1 Configuration Drawings

7.2 Reports

7.3 Operating Procedures

7.4 Test Plans

8.0 MISCELLANEOUS CONSIDERATIONS

8.1 Operating Environment

8.2 Longevity

8.3 Packaging, Shipping, Storage, Handling of the CP-probes

8.4 Maintainability

8.5 Staff Qualifications and Training

8.6 Use of Sub-Contractors

8.7 Transfer of Final Product to BUYER 


\subsection{SCOPE}

This specification establishes the requirements for cone penetrometer (CP) soil multisensor and soil sampling probes (CP-probes) engineering, fabrication, and performance. This specification is required as part of the documentation supporting contract procurement for hardware and services. The information also provides a documented technical basis of quality assurance that is required in order to use the final product hardware in an operating Hanford tank farm. The documentation cited in this specification will be incorporated into an operational fielding plan that will address fielding issues and approvals related to the use of the product hardware at Hanford.

The activity described in this specification is currently planned to be performed as two separate phases of work that will be conducted in succession over a two-year period beginning in FY-97 and completing in FY-98. The primary focus of the current specification is Phase I activities. Phase II activities may be referred to as needed in the discussion, however, details of the Phase II specification aspects are yet to be determined (TBD) and will be provided at a later date as a revision to this specification.

\subsection{BACKGROUND}

The CP-probes discussed in this specification are needed to support the Hanford Tanks Initiative (HTI) project. The HTI is an ongoing, four-year project resulting from the technical and financial partnership of the U. S. Department of Energy (DOE) Office of Waste Management (Environmental Management [EM]-30) and the Office of Science and Technology Development (EM-50). One of the subtasks of the HTI project is to characterize the extent of vadose zone contamination in specified (Hanford, Washington, DOE site) tank farms. This aspect of the HTI effort has been identified as contaminant plume technology implementation. The overall objective of the HTI project contaminant plume technology implementation and demonstration task is to map the location, extent, and contaminant concentration gradient of a single shell tank (SST) leakage-derived plume. This effort is planned to take place over a minimum two-year period (fiscal years 1997 and 1998). A deployment activity to accomplish this objective, using the hardware discussed in this specification, is planned to take place in the 200 East Area 241-AX Tank Farm during the period of FY-98 and FY-99. This task will focus on the backfill soils and vadose zone surrounding tank AX-104 in the 241-AX tank farm on the DOE Hanford Site.

The general functions of the CP-probes are to obtain data regarding waste leakage/contaminant plume extent and content in the soils surrounding SSTs. During the plume characterization effort the 241-AX tank farm soils will be interrogated (using cone penetrometer-deployed sensors and samplers) for traceable contaminants of potential concern (COPC) including metals and gamma emitting radionuclides. The general probe technology and deployment goals of HTI include the following:

- Obtain soil and data samples for analytical speciation of the AX-104 tank [waste] contaminant plume 
- Demonstrate the capability to obtain multiple soil samples during a single, cone penetrometer probe deployment event

- Detect and avoid sub-surface metal objects during CP probe deployment

- Employ reusable multi-sensor and soil sampling probes

- Demonstrate the capability to seal CP penetration points upon extraction of the CP probes.

The CP-probes will provide new data about an expanded suite of potential plume constituents, and that information will be combined with existing historic data to support waste retrieval and tank/tank farm closure decisions. These SST vadose zone characterization tools will contribute needed information to waste retrieval and storage functions.

\subsection{TECHNICAL OVERVIEW}

The cone penetrometer tool is an enclosed tube that contains sensing or sampling technologies that are pushed by a hydraulic device connected to a small diameter pipe (usually less than $5.0 \mathrm{~cm}$ ( 2 inches) dia.) into the ground using massive force. The CP pushing platform is typically moved to the push location by driving it into position onboard a truck or by crane lift from a transport trailer. Once the CP platform, or truck, is in place, heavy weights are attached to achieve a maximum push pressure. $\mathrm{CP}$ piping strings of 1 meter ( 3.3 feet) length are slowly pushed into the ground at a rate of $2-3 \mathrm{~cm} / \mathrm{sec}(0.1$ feet) using hydraulic gripping tools connected to the CP platform.

The tip of the CP piping string is pointed and hardened in order to move more easily through the soil. The pushing operation includes the use of safety features and procedural considerations for both the physical management of the CP push platform and the guidance and deployment of the CP pipe. Careful planning and procedure preparation are typically associated with both the placement of the $\mathrm{CP}$ platform prior to the push, and the deployment of the CP piping strings and probes.

The CP-probes described in this specification are two separate and unique, cone penetrometerdeployable, instrument and hardware "modules" (one for passive analytical instrument interrogation of soils, and one for taking actual grab samples of soils at specific depths). The probes will be incorporated into (i.e., contained within) standard, commercially available, $\mathrm{CP}$ piping strings that will be deployed in the arid soils of the Hanford, Washington DOE Site. The probes will be deployed by the $\mathrm{CP}$ by attaching them into the overall $\mathrm{CP}$ piping string and pushing them into a subsurface position as part of a series of piping segment. In this way they are essentially additional sections of CP pipe (approximately 1 meter in length) that are screwed into position along with all the other piping segments. The multisensor probe will be placed in the first position of the CP piping string so that maximum depth can be achieved for data collection. This is also true for the soil sampling probe, which will be at the tip of the CP string in order to obtain soil samples from the "front" of the push. During deployment the instruments within the multisensor probe will be used to obtain 
electronic data on soil characterization using analytical instrumentation (i.e., soil stratigraphy, gamma spectroscopy system, and xray fluorescence system). The soil sampler probe will be used to withdraw soil samples, at specific depths and locations, from a different/separate CP push hole, that will be created in close proximity (expected to be less than $1 / 2$ meter ( 18 inches)) to sensor probe. The sensor probe will also include commonly used CP devices that will contribute to piping deployment control (magnetometer and inclinometer), and indications of basic soil characteristics (tip and sleeve pressure). The possibility of incorporating a grouting tube (for closure of the $\mathbf{C P}$ hole upon withdrawal) will also be pursued as a goal of the sensor probe engineering effort.

\subsection{CONE PENETROMETER PROBE REQUIREMENTS}

The CP probe(s) will have two primary functions: soil multi-sensor (using a gamma spectroscopy system and $\mathrm{x}$-ray fluorescence system (XRF)) and multi-sample soil sampling. These functions will be implemented as separate, independent probes.

\subsection{General Requirements for CP Probes}

Both CP probe types (i.e., multisensor and sampler) will have similar engineering, configuration, and performance features and capabilities that will enable compatibility with existing $\mathrm{CP}$ deployment tools and to fulfill the overall goal to deploy at Hanford, in the 200 East area, 241-AX tank farm. These minimum requirements include the following:

- Compatibility with existing CP piping thread standards and piping dimensions to the greatest extent possible

- $\quad$ Compatibility with the CP push capabilities and operating conditions of the Hanford CP platform (size of probe/pipe in diameter and length, method of storage preparatory to deployment, etc.). The SELLER should make every effort to reduce the likelihood of incompatibility with of the product CP-probes with the Hanford CP platform

- Engineered capability, to the greatest extent possible, to survive deployment into Hanford soils, and under push pressures and anticipated $\mathrm{CP}$ loading that may be possible using the Hanford $\mathrm{CP}$ platform (maximum 35 - 40 tons push pressure/retraction force). The unpredictability of subsoil conditions and the potential for probe damage or breakage during $\mathrm{CP}$ deployment is acknowledged. However, the engineered configuration and features of the probes should attempt to reduce this potential as much as possible, e.g., the probe may be structured from heat treated to appropriate Rockwell hardness rating.

- Probes must be capable of deployment and functioning at a depth of 15 - 46 meters (50 - 150 feet) in the vadose zone, backfill soils, and native soils in and around the Hanford 200 East SST tank farm (specifically 241-AX tank farm) 
The CP-probes should be engineered to function under normal/routine atmospheric and geologic conditions anticipated during Hanford deployment (e.g., assembly, decontamination, deployment/push, etc.) and within the operating tank farm environment

- The data collection format and driver software (from the multisensor instrument systems) must be compatible with current industry standards and especially with Hanford Site platforms (e.g., DOS, Windows/IBM compatible computer systems). Electronic and hard-copy printout of multisensor data is required. Engineering and performance decisions made within Phase I shall address the fact that the Phase II effort will require a Hanford Site-compatible data collection and software driver requirement.

- There are no initial engineering requirements regarding voltage and power use within the multisensor probe. However, the SELLER shall provide voltage and power parameters within the initial project phase so that the information can be factored into the BUYER's Fielding Plan safety analysis preparation effort

- Probe engineering shall accommodate the need for field maintenance before, during, and after deployment (e.g., disassembly, calibration check, repair, etc.)

\subsection{Multisensor Probe}

The multisensor probe will include, at a minimum, a gamma spectroscopy system, an x-ray fluorescence system, a magnetometer, inclinometer, and basic soil stratigraphy package (cone and sleeve sensors). Sensor data will be used to provide a depth profile of soil characteristics and plume contaminants (extent and content). Sensor data reports from the multisensor probe shall include analyte values (i.e., correlation with soil stratigraphy), uncertainty/statisticals, and depth correlations (i.e., values produced vs specific depths). All technologies integrated into the multisensor probe shall incorporate commercially available components and/or newly available sensor technologies (i.e., no new sensor development work required).

\subsubsection{Gamma Spectroscopy (GS) Detector System}

The GS detector system shall be capable of discriminating and measuring primary gamma-emitting isotopes of interest (as noted in performance guidelines, below) when deployed at anticipated soil depths. At the completion of the configuration/engineering phase, and prior to completion of the GS system fabrication stage, the SELLER shall provide the BUYER will a complete summary of planned GS system operating parameters and anticipated capabilities for review.

\section{Engineering/configuration guidelines}

- The gamma spectroscopy detector system must be capable of operation within the anticipated CP pipe housing (i.e., consideration must be given to pipe housing materials, thickness, assembly constraints, etc.). 
Heat and temperature control/consideration (due to operation of instruments) must be addressed during probe engineering. Data collection must be correlated under anticipated, variable deployment and operating temperature conditions

- The GS detector system must be capable of operating both concurrently or alternately with the XRF system

- Engineering and configuration of the GS detector system shall allow for field verification of operability within established performance parameters (e.g., quality control - such as checking a source prior to deployment) before, during, and after deployment

\section{Performance guidelines}

- The probe must include the capability for a user-selectable count period (anticipated nominal count period will be from $10-10,000$ seconds).

- The probe must be able to count for the pre-set count period during planned CP pipe deployment push intervals (anticipated to be approximately $1 / 3$ meter per cycle)

- The GS system must include provision for temperature compensation over the range of 40 $120^{\circ} \mathrm{F}$

- The GS detector system must be capable of operating both concurrently or alternately with the XRF system

- The GS system must be capable of detecting and measuring gammas in the energy range of 100 $2000 \mathrm{keV}$ within the practical limits of Hanford natural soil. The detection and measurement of Cesium-137 contamination, at a minimum detection limit of 100 picocuries/gram, is of particular interest and the probe will be optimized for this goal. Other isotopes will be detectable commensurate to the Cesium optimization. All discernable gamma-emitting radio-isotopes shall be detectable by the system.

- The GS detector shall be optimized for a sensitivity range of view compatible with the planned nominal depth increment requirement of the $\mathrm{CP}$ push/deployment system (i.e., 1/3 meter per $\mathrm{CP}$ pipe string push interval).

- The GS system must be capable of withstanding the anticipated CP push conditions (mild shock and vibration) anticipated in the arid native soils of the Hanford Site. (Recommend that the SELLER review performance documentation prepared during previous $\mathrm{CP}$ and borehole drilling deployments at the Hanford Site) 


\subsubsection{X-ray Fluorescence System}

The XRF system will be used to detect metals contamination. The XRF system shall be capable of discriminating and measuring primary elements of interest (as noted in performance guidelines, below) when deployed at anticipated soil depths. At the completion of the configuration/engineering phase, and prior to starting the XRF system fabrication stage, the SELLER shall provide the BUYER with a complete summary of planned XRF system operating parameters and anticipated capabilities for review.

\section{Engineering/configuration guidelines}

- The XRF instrument shall be totally enclosed within the CP pipe "housing". A single, small diameter ( approximately $1 / 2$ inch), $x$-ray transparent, viewing material will allow for interrogation of soil that is immediately adjacent to the sensor probe.

- Control and/or detection of heat and temperature (due to operation of instrument and due to deployment environment) within the instrument, shall be addressed during engineering and configuration

- The XRF system configuration and operation shall accommodate at-site (top-side) measurements of a soil sub-sample (i.e., sample split) for correlation with laboratory analysis and down-hole data

- The XRF system must be capable of obtaining data under anticipated (i.e., Hanford Site), variable deployment and operating temperature conditions. The system must include provision for operation in a temperature range of $40-120^{\circ} \mathrm{F}$ (both up-hole/surface and downhole/subsurface conditions)

- $\quad$ The XRF system must be capable of withstanding the anticipated CP push conditions (mild shock and vibration) anticipated in the arid native soils of the Hanford Site. (Recommend that the SELLER review performance documentation prepared during previous $\mathrm{CP}$ and borehole drilling deployments at the Hanford Site)

- $\quad$ Engineering and configuration of the XRF system shall allow for field verification of operability within established performance parameters (e.g., quality control - such as checking a standard prior to deployment)

- The XRF system shall include an interlock system to protect against personnel exposure to $\mathrm{x}$-ray radiation (i.e., during normal operation and handling)

- The XRF system must be capable of operating both concurrently or alternately with the GS detector system 


\section{Performance guidelines}

- The XRF sensor must be capable of detecting, at a minimum, the presence of uranium (U), zirconium $(\mathrm{Zr})$, iron $(\mathrm{Fe})$, chromium $(\mathrm{Cr})$, and lead $(\mathrm{Pb})$ (i.e., the major elements of interest)

- The XRF sensor must provide a minimum detection level of $100 \mathrm{ppm}$ for the elements of interest (i.e., $\mathrm{U}, \mathrm{Zr}, \mathrm{Fe}, \mathrm{Pb}$, and $\mathrm{Cr}$ )

- The XRF system must be capable of operating both concurrently or alternately with the GS detector system

- The XRF system must operate and produce spectra within a (potentially) gamma-contaminated plume up to $100 \mathrm{mrem} / \mathrm{hour}$

- $\quad$ The XRF system must be capable of prescribed detection limits using a maximum 3 minute acquisition period (Note: This acquisition period is related to the planned nominal CP push cycle interval).

\subsubsection{Soil Stratigraphy}

Standard CP soil stratigraphy detection sensors should be incorporated into the multisensor probe. These sensors typically provide data regarding CP cone and sleeve pressures. The SELLER may incorporate these sensors into the magnetometer/inclinometer module (Section 4.1.4), if technically achievable, or in any other location within the overall probe that may become available, as long as the mission/goals for the XRF and GS sensors are not jeopardized. Every effort should be made to include these sensors and the final decision regarding their incorporation or omission should be arrived at jointly between the BUYER and SELLER during the probe engineering/configuration phase.

\subsubsection{Magnetometer and Inclinometer}

A magnetometer shall be included in the multisensor probe to provide the capability to detect [ferrous] metal objects in the path of the probe tip during deployment. An inclinometer will provide information about the CP pipe string tip (including sensor probes) inclination-off-vertical when at depth. Both of these sensors provide essential information to ensure that the probe is not moving "blindly" into the soils surrounding the target tank. The function of these sensors is considered essential to enabling, to the greatest extent possible, a safe and controlled push into tank farm soils.

A magnetometer shall be included in the multisensor probe to provide indication of ferrous objects directly in the path, and in close proximity, of the CP pipe/probe tip. The magnetometer must produce these indications in expected Hanford soil conditions.

Indications/data from the magnetometer and inclinometer must be adequate and appropriate to allow for the Hanford CP platform CP push controls to respond and halt the push action in sufficient time to avoid hitting a detected object. 
Indications/data from the magnetometer should be sent up-hole in a data format that is compatible with the computer software/hardware capabilities of the Hanford CP platform, and as noted in the general probe requirements cited above.

- An inclinometer shall be included in/with the multisensor probe to provide indication of change in the angle of deflection of the CP piping/probe tip out of a vertical direction of travel. The purpose of this requirement is to determine whether the tip is out of vertical alignment as well as to determine approximately where the tip is located with respect to a perfectly vertical path, and where the probe could be heading.

The BUYER acknowledges that the SELLER will not be responsible for the interface and performance of third-party inclinometer and magnetometer components that may be integrated into the overall multisensor probe. The SELLER shall advise the BUYER of the need to ensure the successful interface of such third-party items to the Hanford CP platform.

\subsubsection{Grouting Module}

The overall deployment strategy for the CP-deployed soil sensor probe includes a provision to "close", or plug, the hole once soil/plume interrogation has been completed. The preferred method to accomplish this goal is to incorporate a grouting capability into the soil sensor probe configuration. If this is not technically feasible then the grouting action may be accomplished with a separate, follow up push specifically for hole grouting/closure. This specification acknowledges the potential technical difficulties of incorporating the grouting capability into the sensor probe and requires that the SELLER attempt to engineer a configuration that can fulfill this requirement. If determined not to be technically achievable, then the SELLER is requested to document the basis for this decision. Every effort should be made to include the grouting capability and the final decision regarding incorporation should be arrived as early as possible during the task, and jointly between the BUYER and SELLER during the probe engineering/configuration description phase.

Based upon previous experience using the $\mathrm{CP}$ technique at Hanford, the engineering of the grouting module should consider the need to "cycle" the CP piping string (i.e., move the pipe up and then down again for several inches of travel in order to release side load pressures). This cycling action is anticipated to be a part of the deployment strategy to reach maximum depth in the Hanford soils. If the grouting capability is incorporated into the multisensor probe, the cycling deployment action should be accommodated either by design or by a combination of design and a variation in the recommended/planned deployment action. The grouting module feature must not interfere with the function of the multisensor instrumentation operations or capabilities.

\subsubsection{Umbilical (signal) Cable to Multisensor Probe}

An umbilical cable shall be provided to connect the multisensor probe instrumentation (i.e., GS and XRF systems) to surface data collection devices (i.e., computers). The umbilical cable is an essential part of the overall deliverable for this task and will play an essential role in the collection of data from the probes when they are actually deployed. The umbilical cable shall be included in the 
configuration/design stage and must also be included in the final performance and acceptance tests. The following guidelines shall be followed, at a minimum, regarding the umbilical cable engineering and performance

\section{Engineering/configuration guidelines}

- $\quad$ Provide sufficient bending flexibility to allow deployment within a series of multiple CP piping elements

- Dimensions (i.e., diameter) must be optimized to accommodate all sensor cable needs while at the same time allowing for $\mathrm{CP}$ pipe assembly, disassembly, and deployment conditions

\section{Performance guidelines}

- $\quad$ Maintain signal integrity

- $\quad$ Address friction, abrasion, wear, within the CP pipe during deployment

- Prevent "cross-talk" of power and signals in wires or establish procedures for collection of cross-talk free data from the cable (e.g., alternating GS and XRF data collection)

\subsection{Multi-sample Soil Sampler Probe}

The soil sampling probe will be used to obtain discrete (multiple) soil samples at specified/desired depths in areas where contaminants are suspected or have been found. These samples will be fieldassayed at the push location, then packaged and submitted for laboratory analysis. Soil samples are planned to be taken in close proximity to the location where the initial multisensor probe instrumentation indicated the potential for contamination (i.e., plume presence). The planned approach using a $\mathrm{CP}$ enables sampling from the most promising locations and retrieving only the desired amount of soil needed for analysis.

\section{Engineering/configuration guidelines}

- The probe shall be compatible with existing CP piping components planned for use during the Hanford deployment task

- The sampling probe shall function completely contained within the CP piping string except for the inlet sample chamber into which a small core of soil will be pushed and retained

- The sampling probe shall be engineered to provide capability to obtain a minimum of five (5) samples during a single $\mathrm{CP}$ push event 


\section{Performance guidelines}

- $\quad$ Provide for retrieval of the soil sample/container from inside the CP piping string without having to withdraw any of the CP pipe

- To the greatest extent possible, minimize the opportunity for internal CP piping contamination, and cross-contamination and mixing of samples when multiple samples are taken

\subsection{MATERIALS OF CONSTRUCTION}

The CP-probes are planned for fielding in the arid soils of Hanford, Washington, in the 200 East tank farms area.

- The construction and materials for the probes must consider/address the anticipated deployment conditions, e.g., soil characteristics, potential radiation contamination.

- Consideration of probe housing material hardness will relate to the amount of anticipated abrasion (scoring and scratches) due to Hanford soils.

\subsection{PERFORMANCE VERIFICATION}

Verification action and documentation is required to ensure that the requested CP-probes address the performance and engineering requirements of this specification. Verification will be achieved by completing acceptance tests and compiling requested documentation.

\subsection{Acceptance Testing}

Acceptance testing will include three basic types of tests: vendor acceptance tests (VATs), general construction acceptance tests (CATs), and final acceptance test procedures (ATPs). All acceptance testing will be the responsibility of the SELLER and will be successfully completed before the equipment is released for transfer and/or shipping. Final acceptance test procedures and test reports will be prepared and included as part of the SELLERs information and report submittals. Acceptance test activities (i.e., test plans - Section 7.4) will be proposed by the SELLER and approved by the BUYER and may include focus on such product aspects as:

- Confirmation that the requirements of this specification have been met

- $\quad$ Fabrication and cleanliness inspections

- Checkout of wiring continuity and electrical protective devices 
- $\quad$ Calibration of instruments

- Testing of all instrumentation loops to ensure they function properly and respond within required times/parameters

- $\quad$ Adjustment and setting of controllers, limit switches, and other similar devices

Equipment bench-testing and laboratory checkout

- $\quad$ Performance confirmation that the probes operate as a complete unit (coupled with a CP string) as planned/required

VATs will be performed by the SELLER to demonstrate that fabrication, assembly, installation, construction, and performance requirements cited in this specification have been met. The VATs will be performed at the SELLER's facilities. The SELLER will develop and submit test procedures to the BUYER, as required and appropriate for the equipment procurement specifications. These procedures will be reviewed and approved by the BUYER to ensure that testing specified is adequate to demonstrate compliance with equipment specifications. Performance of the VATs by the SELLER will be witnessed by members of the BUYER staff (i.e., HTI staff) where deemed appropriate.

The SELLER will perform CATs on individual components and subsystems during fabrication/assembly of the probes. The CATs should include standard construction tests such as cleanliness inspection, electrical continuity checks, pre- and post-installation checks, as appropriate. The CATs may be conducted according to existing SELLER guidelines and practice. The CATs shall be conducted by the SELLER and documented as part of the overall task records. The SELLER will perform and monitor all CATs to ensure that proper test documentation is prepared and included as part of the final submittal documentation. The CATs may be observed by the BUYER, or the documentation may be provided to the BUYER, when requested during the course of the task.

The ATPs will represent the final testing performed by the SELLER and witnessed by the BUYER before the equipment will be released for shipment/transfer. The SELLER will perform and/or monitor all ATPs and ensure that proper test documentation is prepared and included as part of the vendor information. The ATPs will be prepared, issued, and performed by the SELLER.

\subsection{Calibration of Instruments}

The instrument modules of the multisensor probe (i.e., GD and XRF systems) will require calibration in order to 1) produce the needed data and 2) to establish credibility and certifying documentation for that data. The purpose of this calibration documentation is to convey to reviewers the validity of calibration sources, qualification of resources applied to the calibration process, and the application of proper procedures for handling and use of calibration equipment and sources. The SELLER shall submit documents, along with other task reports, that describe the certification standards applied, the calibration procedure(s) that is used, and verification of the credentials of certifying staff and the 
equipment employed.

The overall task is expected to involve calibration steps for the separate GS and XRF systems, and for the assembled multisensor probe, during both the Phase I and the Phase II periods. At the end of Phase I calibration activities, the calibration action(s) will be statused and summarized as part of the Phase I acceptance testing process. The decision to close out the calibration activity, or to leave that effort open for continuation into Phase II, will be arrived at by discussion between the BUYER and the SELLER prior to the start of the calibration task, during Phase I. The following list summarizes major calibration-related topics that should be addressed:

- $\quad$ The SELLER shall provide the BUYER with calibration procedure documents for review and comment prior to initiating calibration efforts

- Where sub-contracted calibration tasks are performed, the BUYER and SELLER shall jointly review calibration procedure documentation

- Calibration documentation shall include such records as, 1) certification of calibration standards, 2) calibration procedures, 3) calibration data, 4) records of calibration equipment and staff credentials, and 5) a final calibration report

- Calibration documentation and certification procedures shall show traceability of reference measurements to National Institute of Standards and Technology (NIST) or American Society for Testing Materials (ASTM) certification

- Where calibration efforts are sub-contracted by the SELLER, the SELLER shall ensure that the sub-contractor fulfills the SELLER's obligations and requirements for calibration

- Calibration shall reflect measurements related to the target environment of use (i.e., Hanford Site soils and tank farm conditions) and shall confirm performance to support the engineering and performance requirements cited in this specification

\subsection{DOCUMENTATION}

The SELLER shall prepare and maintain documentation during the course of the task. In addition to routine status communications (see Statement of Work (SOW) attached with Purchase Order No. A08285), documentation relating to compliance with this specification shall be maintained and compiled into a final summary report for transfer to the BUYER at the completion of the task. Performance verification documentation (Section 6), any relevant final configuration drawings of the requested hardware, and summary reports, from the SELLER and any subcontractors to the SELLER, shall be compiled for transfer to the BUYER at the completion of the task. Documentation that is considered part of, and essential to, this task include: configuration drawings, reports, test plans, acceptance test documents, operating procedures, and calibration/verification data. These content and submittal of these items shall be detailed between the BUYER and SELLER as part of the initial engineering and configuration phase of the task. All requested/required documentation shall be transferred to the 
BUYER at the completion of the task (Phase I addressed within this specification version) .

\subsection{Configuration Drawings}

Configuration drawings that convey the design of the requested probes/hardware shall be incorporated into the final task documentation. In particular, drawings that document basic engineering, physical configuration/layout, and construction should be prepared and conveyed to the BUYER. These drawings will be used to document the final probe configuration upon completion and to assist with future reference, maintenance, and modification, if needed, after the hardware is conveyed.

\subsection{Reports}

Periodic status reports and final task reports shall be prepared to support this work. The SELLER shall compile all required documentation, as stated in this specification (and in the SOW attached with Purchase Order No. A-08285), as a deliverable. The format and Quality Assurance for these reports should be consistent with current SELLER/Department of Defense standards. The SELLER should recognize that the completeness and quality of the reports and data supporting the subject task are essential to ensure that the final product (CP-probes) will be allowed for use in the Hanford tank farms operating environment.

\subsection{Operating Procedures}

Basic operating procedures for the requested CP-probes shall be prepared and conveyed at the completion of the task. These procedures are expected to closely match the elements of the acceptance procedures. The operating procedures will be used as field checklists during final deployment and should address operational activities related to field setup, checkout, deployment, breakdown, and return to storage. The operating procedures will also be used as a reference base for both SELLER and BUYER to establish the safe and appropriate sequence of actions to emplace and use the CP-probes.

- Operating procedures prepared during Phase I do not have to include discussion of instrument operation pertaining to data gathering and data transfer by computer control equipment.

- $\quad$ The BUYER shall provide the SELLER with operating procedure documents for review and comment prior to release, and prior to completion of the overall task (Phase I and Phase II).

Summary operating procedures should be compiled during Phase I, and can consist of modified bench test and acceptance test procedure documents. 


\subsection{Test Plans}

The SELLER shall prepare detailed test plans that will be submitted to the BUYER for review, approval, and witnessing, as needed. Tests plans will document the acceptance and operational testing that will be conducted to establish that the CP soil multisensor and soil sampler probes are properly built and will function as planned/designed when placed into service. Test plans should include, at a minimum, the following information:

- Traceability to the BUYER's purchase order document number

- Description of what is being tested (e.g., component, assembly, performance, subassembly, etc.)

- $\quad$ Sequential test steps

- Sequential points/items within test steps that must be performed

- $\quad$ Method that is used to performed the test (i.e., characteristic or attribute evaluated, report form used, fulfilment of purchase order requirement, etc.)

Subsequent revisions or modifications to test plan documentation that has already undergone BUYER review/approval will require re-review by the BUYER prior to implementation of changes.

\subsection{MISCELLANEOUS CONSIDERATIONS}

\subsection{Operating Environment}

Engineering and construction of the CP-probes must consider and address the ultimate conditions at the planned deployment location (i.e., Hanford DOE Site, Washington).

Radiation contamination control and decontamination of the probes during the hot deployment inside a tank farm must be considered. The fabrication/design of the probes must include and document decisions regarding materials of construction in light of the anticipated deployment environment.

Examples:

Excessive exterior wear on the probe surface (during the push action into Hanford soils) may translate into difficulty for decontamination efforts and may limit the reusability of the probes.

The engineering/configuration, materials, wiring, and operation of construction must address anticipated dust, moisture, humidity, heat, and cold conditions during actual deployment at the Hanford Site location. 


\subsection{Longevity}

The expected lifetime of these CP-probes, under normal operating conditions is 3 - 5 years following SELLER-recommended maintenance. The currently planned operating period for the subject probes is a minimum of two years under normal operating conditions (i.e., Hanford deployment in tank farm). This period is expected to be achievable with normal usage and storage modes per directions from the SELLER. The SELLER shall consider this planned/anticipated period of use as part of the engineering requirements for the probes (e.g., materials, robustness of design, maintenance capability, etc.). The SELLER acknowledges that "normal" operating conditions do not include CP deployment equipment misuse or CP pipe/probe structural failure due to downhole pressures/conditions. The SELLER shall provide recommended operating and storage procedures to maximize longevity.

\subsection{Packaging, Shipping, Storage, Handling of the CP-probes}

When shipping, storage, or handling of the CP-probes is required the SELLER will provide:

- $\quad$ Appropriate protection from shock and dropping during shipping and handling

- $\quad$ Stipulation of appropriate storage environmental conditions to ensure operability and longevity

- Instructions regarding unpackaging and special instruments for overall probe preparations prior to normal usage, or prior to extended storage

- Instructions regarding the packaging, storage, and handling of the CP-probes during use/operations and during non-operational (i.e., storage) periods, in order to achieve the engineered longevity (Section 8.2).

- Provide any instructions and/or requirements for recalibration or realignment of the CP-probes prior to, during, or after use in the field

\subsection{Maintainability}

During the planned period of intended use, and for periods of additional use and storage, the CP-probes will be in the care of and maintained by the BUYER. The SELLER shall provide the BUYER with sufficient, documented, instruction and information to allow for maintenance of the CP-probes in good working order, by the BUYER, following conveyance without requiring the services of the SELLER.

- In addition to the operating procedures (Section 7.3) and the acceptance procedures (Section 6.1) the SELLER shall provide the BUYER, at the time of conveyance, with appropriate instructions, documentation, and call-out of special or needed tools, to perform general use of the probes, including installation/incorporation into the $\mathrm{CP}$ push piping string and field testing 
The configuration and construction of the probes shall provide for disassembly to achieve required maintenance and calibration

\subsection{Staff Qualifications and Training}

Personnel selected to perform the work/activities to fulfill this specification and the related purchase order (Purchase Order No. A-08285) shall have the experience and/or training commensurate with the work, complexity, or special nature of the activity.

\subsection{Use of Sub-Contractors}

The SELLER shall ensure that all sub-contracted work will be performed in conformance with the guidance and requirements provided in this specification. The SELLER shall be responsible for compiling and conveying, from sub-contractors, all required documentation and information that is requested from the BUYER at the SELLER's level.

\subsection{Transfer of Final Product to BUYER}

Phase I of this task is planned to complete by the end of FY-97. Phase II is planned to start, and continue with the overall effort into the 1st and 2nd Quarters of FY-98. Actual/physical transfer and conveyance of the deliverable CP-probes to the BUYER may not occur at the end of Phase $\mathrm{I}$, and is TBD, depending on budget and related HTI schedule issues. This specification describes the transfer and completion of the task product, to the BUYER, assuming completion and closure of the task at the end of Phase I. The BUYER and the SELLER shall determine, prior to the completion of Phase I acceptance testing, whether the probes should remain in the possession of the SELLER for Phase II work. The following items apply to transfer and conveyance to the BUYER when the task is determined to be at completion (i.e., end of Phase I, or end of Phase II).

- $\quad$ Completion of the task shall be indicated by: signoff/approval of acceptance tests, completion and acceptance of all required documentation by the BUYER, receipt of the deliverables by the BUYER

- Packaging and shipment to the BUYER shall be conducted to provide safe conveyance to the BUYER and to ensure that all shipping, handling, and storage requirements (Section 8.3) are met 


\section{DISTRIBUTION SHEET}

\begin{tabular}{|c|c|c|c|c|c|}
\hline \multirow{2}{*}{$\begin{array}{l}\text { To } \\
\text { Distribution }\end{array}$} & \multirow{2}{*}{\multicolumn{3}{|c|}{$\begin{array}{l}\text { From } \\
\text { Numatec Hanford Co., Process } \\
\text { Systems Design }\end{array}$}} & \multicolumn{2}{|l|}{ Page 1 of 1} \\
\hline & & & & \multicolumn{2}{|l|}{ Date $5 / 2 / 97$} \\
\hline \multirow{2}{*}{\multicolumn{4}{|c|}{$\begin{array}{l}\text { Project Title/Work Order } \\
\text { Waste Management - HNF-SD-HTI-SDS-001 }\end{array}$}} & \multicolumn{2}{|c|}{ EDT No. $\quad 620513$} \\
\hline & & & & \multicolumn{2}{|l|}{ ECN No. $\mathrm{n} / \mathrm{a}$} \\
\hline \multicolumn{2}{|l|}{ Name } & $\begin{array}{l}\text { Text } \\
\text { With All } \\
\text { Attach. }\end{array}$ & Text Only & $\begin{array}{l}\text { Attach./ } \\
\text { Appendix } \\
\text { Only }\end{array}$ & $\begin{array}{c}\text { EDT/ECN } \\
\text { Only }\end{array}$ \\
\hline $\begin{array}{l}\text { JW B B oom } \\
\text { JJ Huston } \\
\text { DF Iwatate } \\
\text { B Root }\end{array}$ & $\begin{array}{l}H 6-12 \\
H 5-61 \\
H 5-49 \\
H 6-12\end{array}$ & $\begin{array}{l}x \\
x \\
x \\
x\end{array}$ & & & \\
\hline $\begin{array}{l}\text { Central Files (2) } \\
\text { HTI Project Files (2) }\end{array}$ & $\begin{array}{l}A 3-88 \\
H 6-08\end{array}$ & $\begin{array}{l}x \\
x\end{array}$ & & & \\
\hline
\end{tabular}

